\title{
Measurements of anterior chamber depth, white-to-white distance, anterior chamber angle, and pupil diameter using two Scheimpflug imaging devices
}

\author{
Medida da profundidade da câmara anterior, distância branco a branco, ângulo da câmara anterior e \\ diâmetro pupilar usando dois dispositivos de imagens de Scheimpflug
}

Alberto Domínguez-Vicent ${ }^{1}$, Daniel Monsálvez-Romín ${ }^{1}$, Antonio Jesus Del Águila-Carrasco ${ }^{1}$, Santiago García-Lázaro ${ }^{1}$, Robert Montés-Micó ${ }^{1}$

\begin{abstract}
Purpose: To compare the ocular anterior chamber depth, white-to-white distance, anterior chamber angle, and pupil diameter, as measured with two different Scheimpflug imaging devices.

Methods: This transversal study included 80 right eyes from 80 subjects aged from 20 to 40 years. Their spherical equivalents ranged from -4.25 to +1.00 diopters (D) Each eye's anterior chamber depth, white-to-white distance, anterior chamber angle, and pupil diameter, were measured for far vision using both the Galilei G4 (double Scheimpflug camera) and the Pentacam HR (single Scheimpflug camera) systems. Results: Mean anterior chamber depths were calculated as $3.12 \pm 0.23 \mathrm{~mm}$ and 3.19 $\pm 0.24 \mathrm{~mm}$ when measured with the Galilei G4 and the Pentacam HR, respectively. The mean white-to-white distance measured was $11.84 \pm 0.31 \mathrm{~mm}$ and $11.90 \pm$ $0.43 \mathrm{~mm}$ when measured with the Galilei G4 and the Pentacam HR, respectively. Mean pupil diameters were measured as $3.22 \pm 0.58 \mathrm{~mm}$ and $3.22 \pm 0.52 \mathrm{~mm}$ when measured with the Galilei G4 and the Pentacam HR, respectively. Finally, the mean anterior chamber angle was $34.30 \pm 2.86$ degrees when it was measured with the Galilei G4, and $39.26 \pm 2.85$ degrees when measured with the Pentacam HR. A comparative analysis revealed that the Galilei G4 yielded a significantly lower $(P<0.05)$ measurement for the anterior chamber depth, anterior chamber angle and pupil diameter, than the Pentacam HR system. Comparable values $(P>0.05)$ for both devices were obtained for the white-to-white distance measurements. Conclusion: The Galilei G4 and Pentacam HR Scheimpflug systems cannot be used interchangeably because they produce significant measurement differences.
\end{abstract}

Keywords: Anterior chamber/pathology; Pupil/physiology; Corneal topography; Diagnostic techniques, ophthalmological; Photography/methods; Interferometry

\section{RESUMO}

Objetivo: Avaliar a medida da profundidade da câmara anterior, distância branco a branco, ângulo da câmara anterior e diâmetro pupilar usando dois dispositivos de imagens de Scheimpflug diferentes.

Métodos: Este estudo transversal incluiu 80 olhos direitos de 80 indivíduos com idades entre 20 e 40 anos. O equivalente esférico variou de $-4,25 a+1,00$ dioptrias (D). A profundidade da câmara anterior de cada olho, a distância branco a branco, o ângulo da câmara anterior e o diâmetro pupilar, foram medidos para visão de longe usando tanto o Galilei G4 (câmera de Scheimpflug dupla) e os sistemas Pentacam HR (câmera de Scheimpflug simples).

Resultados: A profundidade média da câmara anterior foi 3,12 $\pm 0,23 \mathrm{~mm}$ e 3,19 \pm $0,24 \mathrm{~mm}$, usando o Galilei G4 e o Pentacam HR, respectivamente. A distância média da medida de branco a branco com o Galilei G4 foi 11,84 $\pm 0,31 \mathrm{~mm}$ e com o HR Pentacam foi $11,90+0.43 \mathrm{~mm}$. A média do diâmetro pupilar foi $3.22+0,58 \mathrm{~mm}$ e 3.22 + $0,52 \mathrm{~mm}$, medidos com o Galilei G4 e o Pentacam HR, respectivamente. Finalmente, a média do ângulo da câmara anterior foi de $34,30 \pm 2,86$ graus quando foi medido com o G4 Galileu, e 39,26 $\pm 2,85$ graus com o Pentacam HR. A comparação revelou que o dispositivo Galilei G4 mediu significativamente menor $(P<0,05)$ profundidade da câmara anterior, ânqulo da câmara anterior e diâmetro da pupila do que o sistema de Pentacam HR, enquanto valores comparáveis $(P>0,05)$ entre os dois dispositivos Scheimpflug foram obtidos para as medidas da distância branco a branco.

Conclusão: O Galileu G4 e o Pentacam HR não podem ser usados indiferentemente, devido às diferenças entre os dois aparelhos terem sido significativas sob o ponto de vista clínico.

Descritores: Câmara anterior/patologia; Pupila/fisiologia; Topografia da córnea; Técnicas de diagnóstico oftalmológico; Fotografia/métodos; Interferometria

\section{INTRODUCTION}

The measurement of anterior chamber depth (ACD), white-to-white (WTW) distance, and pupil diameter (PD) is an important step prior to any refractive surgery. In this context, the ACD measurement is useful in determining the appropriate phakic or standard intraocular lens $(\mathrm{IOL})$ power, and in predicting the $\mathrm{IOL}$ vault prior to its implantation. Furthermore, the WTW distance is useful in determining the optimum IOL size, and the PD is essential in determining the optical zone where the laser pattern has to be applied. Also, an anterior chamber angle (ACA) evaluation is essential to establish the risk of angle disclosure ${ }^{(1)}$. Recent technological advances have allowed the ACD, WTW,
$P D$, and ACA measurements to be quantified with the following noninvasive techniques: Scheimflug photography (Pentacam-Galilei), scanning slit topography (Orbscan/Orbscanll), and partial (IOLMaster) and low coherence interferometry (Visante-optical coherence interferometry and Lenstar). However, invasive techniques such as A-Scan or ultrasound byomicroscopy, are still being used to measure ACD in some cases.

The Pentacam HR (Oculus, Wetzlar, Germany) and the Galilei G4 (Ziemer, Switzerland) are two clinical tomographers that are both based on Scheimpflug cameras. Beside corneal parameters, these devices also have the ability to measure the ACD, ACA, PD, and ACA, and they Valencia) awarded to Antonio J Del Águila-Carrasco.

Disclosure of potential conflicts of interest: None of the authors have any potential conflicts of interest to disclose. 
Measurements of ANterior chamber Depth, White-to-White Distance, ANTerior Chamber ANGLe, AND pupil Diameter using two SCHEIMPFLUG IMAGING DEVICES

are now being routinely used in clinical practice. Because of this, we felt that it was important to study the agreement between the Pentacam HR and the Galilei G4 systems regarding ACD, ACA, PD, and ACA measurements. Table 1 shows all previously reported studies that have assessed either the Pentacam/Pentacam HR or the Galilei systems, focusing on measurements of the ACD ${ }^{(1-19)}$ or WTW distance ${ }^{(20-22)}$. However, to our knowledge, a side by side comparative study has not previously been reported. Regarding PD and ACA measurements, there have been no studies published using either the Pentacam/ Pentacam HR or Galilei/Galilei G4 systems. Recently, Domínguez-Vicent et al. (22), assessed the agreement between the Galilei G4 and the Orbscan II systems in order to measure the angle kappa.

Thus, the aim of this study was to compare the ACD, WTW, PD, and ACA measurements obtained using a double-Scheimpflug camera (Galilei G4) and a single-Scheimpflug camera (Pentacam HR) in order to determine whether these devices can be used interchangeably in clinical practice.

\section{METHODS}

\section{Subjects}

This transversal study comprised 80 right eyes from 80 subjects (39 men and 41 women), whose ages ranged from 20 to 40 years (mean \pm standard deviation: $30.36 \pm 7.32$ years). Their spherical equivalent (SE) ranged from -4.25 to +1.00 diopters (D) (mean: $-0.80 \pm$ 2.33 D). Subjects with a best-corrected visual acuity below $20 / 25$, ocular or systemic disease, a history of ocular surgery, intraocular pressure above $21 \mathrm{mmHg}$, or the presence of retinal or optic disk pathology, were excluded from taking part in the study.

Informed consent was obtained from each participant following a verbal and written explanation of the nature and possible consequences of the study. Moreover, this study followed the tenets of the Declaration of Helsinki.

\section{Devices used}

\section{Galilei G4}

The Galilei G4 system is a recent version of the Galilei topographer. This non-invasive optical diagnostic device was designed for the assessment of the eye's anterior segment. It is based on a rotating dual-Scheimpflug camera and a Placido topography system. The images recorded by this device include the cornea, iris, pupil, limbus, anterior chamber, and lens. After each standard 3D scan, this device integrates the Placido and Scheimpflug images in order to generate a $3 \mathrm{D}$ model of the anterior segment. Moreover, this device also includes a LED near/far adjustable fixation target which can be moved in steps of $0.25 \mathrm{D}$ from $-20 \mathrm{D}$ to $+20 \mathrm{D}$.

The Galilei G4 was used to automatically measure the ACD, WTW distance, mean ACA, and PD for far vision. The central ACD was calculated as the distance between the corneal endothelium and the crystalline lens' anterior surface, with a resolution of $0.01 \mathrm{~mm}$. The limbus was fitted to a best-fit ellipse in the top reference image and the WTW distance was then measured as the maximum length in the horizontal direction of the ellipse, also with a resolution of $0.01 \mathrm{~mm}$. Regarding the ACA measurements, these were done by extrapolating the posterior corneal surface and the smoothed surface of the iris, to the point where both curves intersected. This angle of intersection was taken as the ACA, with a resolution of 0.10 degrees. Finally, the PD was fitted to a best-fit circle in the reference top view image.

\section{Pentacam HR}

The Pentacam HR is a non-invasive tomographer that is based on a rotating simple Scheimpflug system. The camera revolves around the optical axes of the eye, to calculate a $3 \mathrm{D}$ model of the anterior segment. The internal software creates a $3 \mathrm{D}$ reconstruction of the anterior segment using the elevation data contained in these images,
Table 1. Anterior eye results obtained in published peer-reviewed studies

\begin{tabular}{|c|c|c|c|}
\hline Reference (no. of eyes) & Device & $\begin{array}{l}\text { Mean } A D^{a} \\
\pm S D^{b}(m m)\end{array}$ & $\begin{array}{c}\text { Mean WTW' } \\
\pm \text { SD }(\mathrm{mm})\end{array}$ \\
\hline \multirow[t]{2}{*}{ Savant et al. $.^{(2)},(50)$} & Pentacam & $3.21 \pm 0.03$ & \multirow{2}{*}{-} \\
\hline & IOLMaster & $3.23 \pm 0.03$ & \\
\hline \multirow[t]{2}{*}{ Nemeth G et al. ${ }^{(3)}$, (42) } & A-Scan & $2.89 \pm 0.49$ & \multirow[b]{2}{*}{ - } \\
\hline & Pentacam & $2.87 \pm 0.40$ & \\
\hline \multirow[t]{3}{*}{ Doors et al. ${ }^{(4)},(66)$} & Orbscan II & $3.25 \pm 0.29$ & \multirow{3}{*}{-} \\
\hline & Pentacam & $3.34 \pm 0.27$ & \\
\hline & Visante OCTe & $3.41 \pm 0.25$ & \\
\hline \multirow[t]{2}{*}{ Woodmass et al.(5), (52) } & Pentacam & $3.82 \pm 0.41$ & \multirow{2}{*}{-} \\
\hline & IOLMaster & $3.78 \pm 0.42$ & \\
\hline \multirow[t]{2}{*}{ Reuland et al. ${ }^{(6)},(82)$} & Pentacam & $3.25 \pm 0.50$ & \multirow{2}{*}{ - } \\
\hline & IOLMaster & $3.20 \pm 0.40$ & \\
\hline \multirow[t]{2}{*}{ Lackner et al. ${ }^{(7)},(60)$} & Orbscan & $3.23 \pm 0.40$ & \multirow{2}{*}{-} \\
\hline & Pentacam & $3.18 \pm 0.38$ & \\
\hline \multirow[t]{3}{*}{ Utine et al. ${ }^{(8)},(42)$} & Orbscan II & $3.49 \pm 0.30$ & \multirow{3}{*}{-} \\
\hline & Pentacam & $3.54 \pm 0.31$ & \\
\hline & IOLMaster & $3.43 \pm 0.29$ & \\
\hline \multirow[t]{4}{*}{ Dinc et al. ${ }^{(9)},(80)$} & Orbscan II & $2.80 \pm 0.29$ & \multirow{4}{*}{-} \\
\hline & Pentacam & $2.93 \pm 0.30$ & \\
\hline & Visante OCTe & $2.98 \pm 0.29$ & \\
\hline & IOLMaster & $3.33 \pm 0.42$ & \\
\hline \multirow[t]{3}{*}{ Elbaz et al. ${ }^{(10)},(22)$} & A-Scan & $3.00 \pm 0.37$ & \multirow{3}{*}{-} \\
\hline & Pentacam & $3.08 \pm 0.38$ & \\
\hline & IOLMaster & $2.99 \pm 0.37$ & \\
\hline \multirow[t]{2}{*}{ Szalai et al. ${ }^{(11)},(46)$} & A-Scan & $3.08 \pm 0.43$ & \multirow{2}{*}{-} \\
\hline & Pentacam HR & $2.89 \pm 0.41$ & \\
\hline \multirow[t]{3}{*}{ Yazici et al..12), (100) } & Orbscan & $2.84 \pm 0.33$ & \multirow{3}{*}{-} \\
\hline & Pentacam & $2.98 \pm 0.33$ & \\
\hline & Visante OCTe & $2.94 \pm 0.34$ & \\
\hline Salouti et al...13), (74) & Orbscan II & $3.54 \pm 0.07$ & \\
\hline & Pentacam HR & $3.25 \pm 0.05$ & - \\
\hline & Galilei & $3.22 \pm 0.05$ & \\
\hline Hashemi et al..(14), (46) & Orbscan II & $3.10 \pm 0.33$ & \\
\hline & Pentacam & $3.26 \pm 0.34$ & - \\
\hline Kim et al...15), (51) & Orbscan II & $3.09 \pm 0.28$ & \\
\hline & Pentacam & $3.23 \pm 0.33$ & \\
\hline O'Donnell et al. ${ }^{(16)},(17)$ & Pentacam & $2.96 \pm 0.32$ & \\
\hline & Visante OCT & $3.03 \pm 0.29$ & - \\
\hline & Lenstar & $2.93 \pm 0.30$ & \\
\hline Huang et al. ${ }^{(17)},(108)$ & Pentacam & $3.78 \pm 0.25$ & \\
\hline & Lenstar & $3.76 \pm 0.24$ & \\
\hline Németh et al. ${ }^{(18)}$, (83) & Pentacam HR & $3.01 \pm 0.34$ & \\
\hline & IOLMaster & $2.95 \pm 0.32$ & - \\
\hline Aramberri et al. ${ }^{(19)},(35)$ & Pentacam HR & $3.04 \pm 0.33$ & - \\
\hline & Galilei & $3.14 \pm 0.32$ & - \\
\hline Salouti et al. ${ }^{(20)},(37)$ & Orbscan II & - & $11.67 \pm 0.29$ \\
\hline & Galilei & - & $12.01 \pm 0.61$ \\
\hline & EyeSys & - & $12.09 \pm 0.87$ \\
\hline Kim et al..(21), (20) & Orbscan II & & $11.56 \pm 0.41$ \\
\hline & Pentacam & - & $11.86 \pm 0.45$ \\
\hline & Visante OCT & & $11.70 \pm 0.47$ \\
\hline
\end{tabular}

$a=$ anterior chamber depth (ACD); $b=$ standard deviation (SD); $c=$ white-to-white (WTW) distance; $d=$ pupil diameter (PD); $\mathrm{e}=$ optical coherence tomography $(\mathrm{OCT})$. 
thus providing information about both the anterior and the posterior surface of the cornea, crystalline lens, and anterior chamber. The device has a red light source that serves as a fixation target, and which can be moved in 0.5 D steps from + 2 D-5 D.

The Pentacam HR was also used to automatically measure the central ACD, WTW distance, ACA, and PD, all for far vision. The central ACD was calculated as the distance between the corneal endothelium and the crystalline lens'anterior surface, with a resolution of $0.01 \mathrm{~mm}$. The WTW distance was calculated automatically from the iris photo, with a resolution of $0.10 \mathrm{~mm}$. The ACA was calculated from the reconstructed anterior segment image, using the angle intersection between the posterior corneal surface and iris, with a resolution of 0.10 degrees. Finally, the PD was calculated as the mean value of the measurement procedure, with a resolution of $0.01 \mathrm{~mm}$.

\section{EXPERIMENTAL PROCEDURE}

Each eye's ACD, WTW distance, ACA, and PD, were measured three times with each device under far-viewing conditions, and an average value was obtained. The order in which these two devices were used was randomized and for each subject and all measurements were performed within a single session. In order to avoid any possible bias related to differences in luminance conditions, both devices were placed in the same room, which remained in complete darkness during the measurements. Moreover, black fabric was placed over both the instrument and the subject in order to avoid any luminance emanating from the computer or any other source. The same specialist, who had experience operating both devices and who was not aware of the study goals, carried out all the experimental measures.

\section{Statistical analysis}

Statistical analysis was performed by means of the SPSS statistical software package SPSS/PC + 10.1 for Windows (SPSS, Chicago, Illinois, USA). A Student's t-test for unpaired data was used to compare the differences in ACD, WTW, ACA, and PD measurements between the Galilei G4 and the Pentacam HR. Differences were considered to be statistically significant when $P<0.05$. To assess inter-device agreements and their interchangeability for the measurement of anterior eye distances, the method described by Bland and Altman for repeated measurements was used ${ }^{(23)}$. The $95 \%$ limits of agreement were computed as the mean difference of \pm 1.96 SD.

\section{RESULTS}

\section{Anterior CHAMBer DePth}

Results revealed that the Pentacam HR yielded significantly larger ACD measurements than the Galilei G4 $(P<0.05)$, with the mean difference being $-0.07 \pm 0.11 \mathrm{~mm}$ (Table 2). Regarding the device agreements, figure 1 shows Bland-Altman plots that represent the difference between both devices against their mean. It can be seen that although the mean ACD difference was close to zero, the spread was highly variable. The $95 \%$ limit of agreement was within $0.43 \mathrm{~mm}$.

\section{White-to-White Distance}

Results revealed no statistical difference between the two systems regarding WTW distances ( $P>0.05)$, with the mean difference being $-0.05 \pm 0.39 \mathrm{~mm}$ (Table 2). However, the wide spread values inferred from figure 2, and the wide $95 \%$ limits of agreement, revealed poor agreement between the device measures.

\section{Pupil diameter}

Results showed that the Pentacam HR produced significantly higher PD measurements than the Galilei G4, with the mean difference being - $0.14 \pm 0.24 \mathrm{~mm}$ (Table 2). The inter-device comparison (Figure 3 ) showed a high variability on the anterior eye measurement (the limit of agreement was within $0.43 \mathrm{~mm}$ ), despite its mean difference being close to zero.

\section{Anterior ChAmber ANGLE}

Results revealed that the Pentacam HR produced significantly higher ACA values than the Galilei G4 $(P<0.05)$, with the mean difference being $4.05 \pm 2.45$ degrees (Table 2). A Bland-Altman comparison (Figure 4) revealed a wide limit of agreement (9.60 degrees) and high spread values.

\section{DISCUSSION}

The aim of the present work was to compare the ACD, WTW distance, PD, and ACA values obtained by the Galilei G4 and the Pentacam HR systems, so as to elucidate whether or not these devices can be considered to be interchangeable in clinical practice when it comes to measuring these parameters.

\section{ANTERIOR CHAMBER DEPTH}

The Galilei G4 produced significantly lower ACD measurements than the Pentacam HR, the mean difference being $0.07 \pm 0.11 \mathrm{~mm}$. Based on the limits of agreement analysis, there is a $95 \%$ chance that the Pentacam HR will measure the ACD between $0.14 \mathrm{~mm}$ shallower and $0.29 \mathrm{~mm}$ deeper than the Galilei G4. This range is large enough to create damage ${ }^{(24)}$ related to the $I O L$ vault. However, this range is not clinically relevant to the $\mathrm{IOL}$ power calculation (IOL power varies by $0.05 \mathrm{D}$ for each $0.10 \mathrm{~mm}$ of $\left.\mathrm{ACD}^{(25)}\right)$. Consequently, it can be concluded that these devices can be used interchangeably to calculate IOL power, but not to predict the IOL vault.

These results agree with previously published studies ${ }^{(14,19)}$. Salouti et al. ${ }^{(13)}$, compared the ACD measurements from volunteers using the Galilei and Pentacam HR systems, concluding that the differences between these devices were within clinically acceptable levels (the highest mean difference and limits of agreement widths being $0.02 \pm$ $0.01 \mathrm{~mm}$ and $0.23 \mathrm{~mm}$, respectively). However, Aramberri et al. ${ }^{(19)}$, concluded that single and dual Scheimpflug camera systems produced significantly different ACD measurements, with the mean difference and confidence interval being $0.10 \pm 0.05 \mathrm{~mm}$ and $0.04 \mathrm{~mm}$, respectively. Thus, further studies are required in order to clarify which Scheimpflug device (Pentacam HR or Galilei G4) measures the ACD at a shallower or deeper level. Despite these differences in results, the differences between the devices were not significant from a clinical point of view regarding $\mathrm{IOL}$ power assessment.

\section{WHITE-TO-WHITE DISTANCE}

The mean WTW distances measured in our study with the Galilei G4 and the Pentacam HR were $11.84 \pm 0.31 \mathrm{~mm}$ and $11.90 \pm 0.43 \mathrm{~mm}$, respectively (mean difference: $0.05 \pm 0.39 \mathrm{~mm}$ ). Regarding the

Table 2. Mean anterior eye distances (expressed mean \pm standard deviation (SD), mean differences, SD, and limits of agreement obtained for the Galilei G4 and Pentacam HR systems for all anterior eye distances

\begin{tabular}{|c|c|c|c|c|c|}
\hline & Galilei G4 & Pentacam HR & $P$ & Mean difference \pm SD & 95\% Limits of agreement \\
\hline Anterior chamber depth (mm) & $3.12 \pm 0.23$ & $3.19 \pm 0.24$ & $<0.05$ & $-0.07 \pm 0.11$ & -0.29 to 0.14 \\
\hline White-to-white distance (mm) & $11.84 \pm 0.31$ & $11.90 \pm 0.43$ & $>0.05$ & $-0.05 \pm 0.39$ & -0.82 to 0.71 \\
\hline Pupil diameter (mm) & $3.22 \pm 0.58$ & $3.22 \pm 0.52$ & $<0.05$ & $-0.14 \pm 0.24$ & -0.63 to 0.34 \\
\hline Anterior chamber angle (degrees) & $34.30 \pm 2.86$ & $39.26 \pm 2.85$ & $<0.05$ & $-4.05 \pm 2.45$ & -8.86 to 0.74 \\
\hline
\end{tabular}




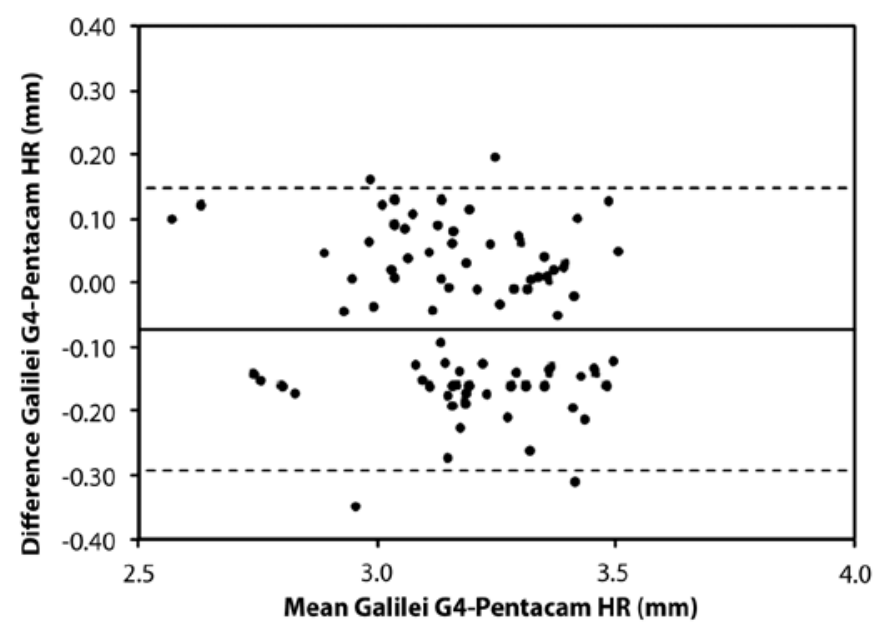

Figure 1. Bland-Altman plot comparing the Galilei G4 and Pentacam HR systems in measuring the anterior chamber depth.

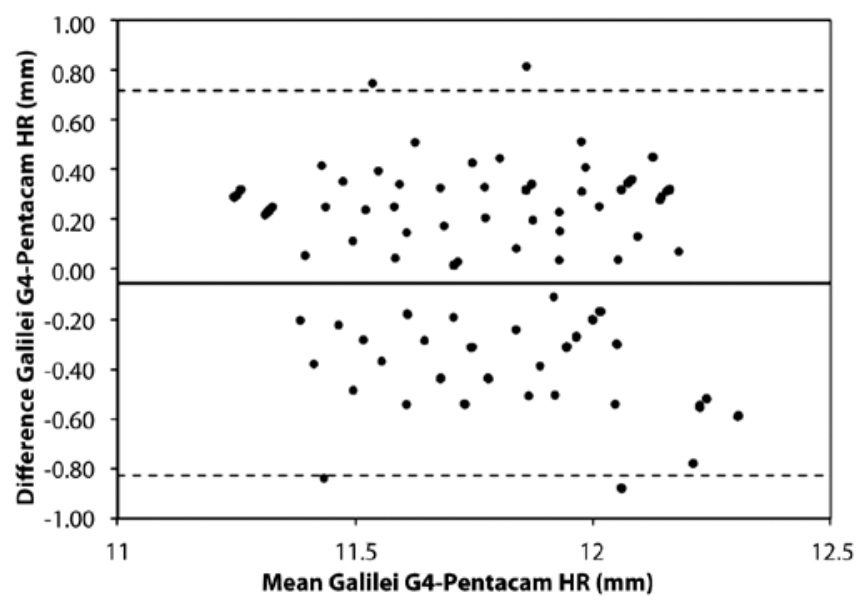

Figure 2. Bland-Altman plot comparing the Galilei G4 and Pentacam HR in measuring the white-to-white distance.

device comparison, the Bland-Altman plot revealed that there is a 95\% chance that the Pentacam HR will measure the ACD between $0.71 \mathrm{~mm}$ shorter and $0.82 \mathrm{~mm}$ longer than the Galilei G4. Although comparable results were obtained between these devices, they are significant from a clinical point of view. Thus, it can be concluded that these devices cannot be used interchangeably to measure this distance.

\section{Pupil diameter}

To our knowledge, there has only been one previously published study regarding the measurement of the PD with a non-invasive anterior segment device ${ }^{(26)}$. In this case two infrared pupillometers were compared with the Orbscanll and two aberrometers (Table 1 summarizes their results). We found lower PD values than the previously reported study, with a mean difference of approximately $3.00 \mathrm{~mm}$. These differences could be due to the different illumination systems used in the studies: infrared light below 1 lux was used for the pupillometers and visible light was used in our study. However, similar results were obtained regarding pupil diameters measured with the Orbscan II(26) and those obtained in the present study.

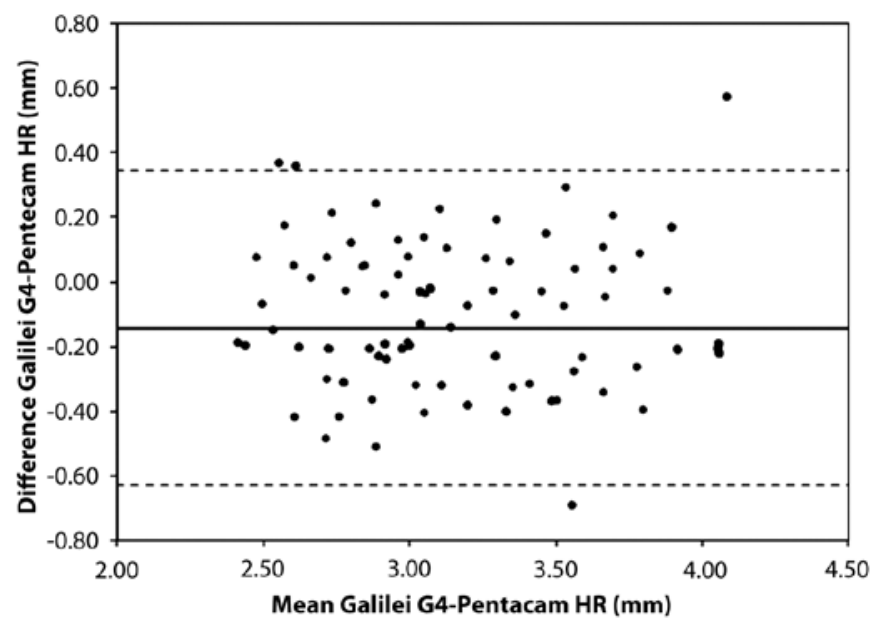

Figure 3. Bland-Altman plot comparing the Galilei G4 and Pentacam HR systems in measuring pupil diameter.

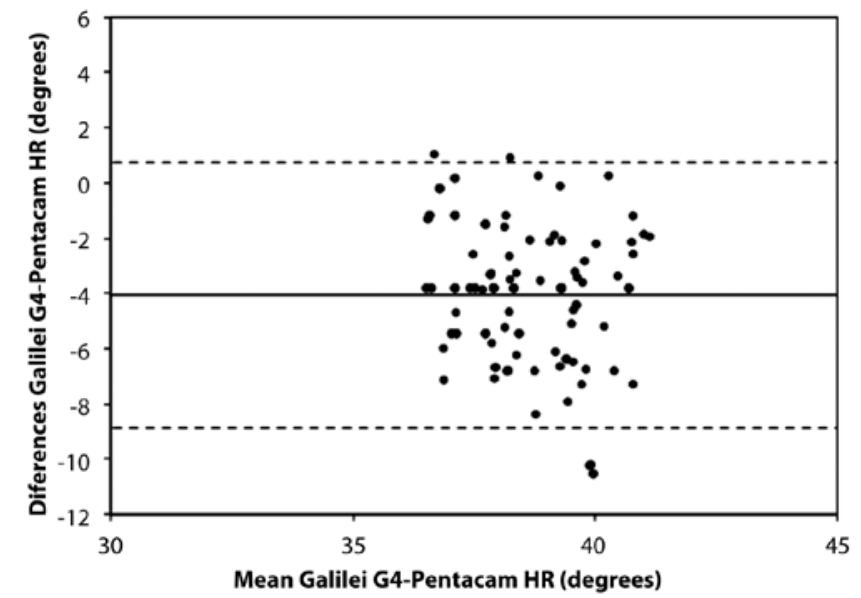

Figure 4. Bland-Altman plot comparing the Galilei G4 and Pentacam HR systems in measuring the anterior chamber angle.

Our results showed that the Pentacam HR measured significantly higher PD values than the Galilei G4 (means of $3.13 \pm 0.52 \mathrm{~mm}$ and $3.22 \pm 0.58 \mathrm{~mm}$, respectively). The device comparison revealed that there was a $95 \%$ chance that the Pentacam HR would measure the PD between $0.34 \mathrm{~mm}$ shorter and $0.63 \mathrm{~mm}$ longer than the Galilei G4. These differences are significant from a clinical point of view regarding the IOL's optic zone ${ }^{(24)}$.

\section{Anterior Chamber ANGLe}

In terms of the ACA, our study revealed a statistically significant difference between the Pentacam HR (mean: $39.26 \pm 2.85$ degrees) and the GalileiG4 (mean: $34.30 \pm 2.86$ degrees) measurements, with the mean difference being $4.05 \pm 2.45$ degrees. These measurements are in close agreement with those obtained by Leung et al. ${ }^{(27)}$, where the trabecular iris angle was measured using slit-lamp OCT (SL-OCT) and the Visante OCT system. In this study the mean ACA measured with the SL-OCT and the Visante OCT was approximately 39.20 and 38.85 degrees, respectively.

Our results revealed that the Pentacam $\mathrm{HR}$ produced significantly higher ACA values than the Galilei G4. The Bland-Altman analysis re- 
vealed a 95\% chance that the Pentacam HR would measure the ACD between 0.74 degrees lower and 8.86 degrees higher than the Galilei $\mathrm{G} 4$. These values are significant from a clinical point of view. Thus, it can be concluded that the two devices cannot be used interchangeably to measure the ACA.

We therefore conclude that the Galilei G4 and Pentacam HR systems cannot be used interchangeably in clinical practice when used to measure the ACD (especially when it comes to assessing the IOL vault), WTW distance, PD, and ACA due to their poor measurement agreements. Finally, it is worth mentioning that there were several limiting factors in this study: first, only two anterior segment tomographers (Pentacam HR and Galilei G4) were included; second, the participants' ages ranged between 20 and 40 years; and finally, only normal corneas of healthy subjects were included. Further studies should attempt to include additional anterior chamber measuring devices, an extended age range, and study the agreement between these devices in postoperative corneas, and in those with defined pathologies.

\section{REFERENCES}

1. Mansouri K, Sommerhalder J, Shaarawy T. Prospective comparison of ultrasound biomicroscopy and anterior segment optical coherence tomography for evaluation of anterior chamber dimensions in Europeans eyes with primary angle clousure. Eye (Lond) 2014;24(2):233-9.

2. Savant V, Chavan R, Pushpoth S, Ilango B. Comparing and intra-/interobserved reliability of anterior chamber depth measurements with Pentacam and IOLMaster. J Refract Surg. 2008;24(6):615-8.

3. Nemeth G, Vajas A, Kolozsvari B, Berta A, Modis L Jr. Anterior chamber depth measu rements in phakic and pseudophakic eyes: Pentacam versus ultrasound device. J Cataract Refract Surg. 2006;32(8):1331-5.

4. Doors M, Cruysberg LP, Berendschot TT, de Brabander J, Verbakel F, Weber CA, et al. Comparison of central corneal thickness and anterior chamber depth measurements using three imaging technologies in normal eyes and after phakic intraocular lens implantation. Graefes Arch Clin Exp Ophthalmol. 2009;247(8):1139-46.

5. Woodmass J, Rocha G. A comparison of Scheimpflug imaging simulated and Holladay equivalent keratometry values with partial coherence interferometry keratometry measurements in phakic eyes. Can J Ophthalmol. 2009;44(6):700-4.

6. Reuland MS, Reuland AJ, Nishi Y, Auffarth GU. Corneal radii and anterior chamber depth measurements using the IOLMaster versus the Pentacam. J Refract Surg. 2007; 23(4):368-73.

7. Lackner B, Schmidinger G, Skorpik C. Validity and repeatability of anterior chamber depth measurements with Pentacam and Orbscan. Optom Vis Sci. 2005;82(9):858-61.

8. Utine CA, Altin F, Cakir H, Perente I. Comparison of anterior chamber depth measurements taken with the Pentacam, Orbscan IIz and IOLMaster in myopic and emmetropic eyes. Acta Ophthalmol. 2009;87(4):386-91.

9. Dinc UA, Gorgun E, Oncel B, Yenerel MN, Alimgil L. Assessment of anterior chamber depth using Visante optical coherence tomography, slitlamp optical coherence tomography, IOL Master, Pentacam and Orbscan IIz. Ophthalmologica. 2010;224(6):341-6.

10. Elbaz U, Barkana Y, Gerber Y, Avni I, Zadok D. Comparison of different techniques of anterior chamber depth and keratometric measurements. Am J Ophthalmol. 2007; 143(1):48-53.

11. Szalai E, Berta A, Nemeth G, Hassan Z, Modis L Jr. Anterior chamber depth measurements obtained with Pentacam HR(R) imaging system and conventional A-scan ultrasound. Ophthalmic Surg Lasers Imaging. 2011;42(2):248-53.

12. Yazici AT, Bozkurt E, Alagoz C, Alagoz N, Pekel G, Kaya V, et al. Central corneal thickness, anterior chamber depth, and pupil diameter measurements using Visante OCT, Orbscan, and Pentacam. J Refract Surg. 2010;26(2):127-33.

13. Salouti R, Nowroozzadeh MH, Zamani M, Ghoreyshi M, Salouti R. Comparison of anterior chamber depth measurements using Galilei, HR Pentacam, and Orbscan II. Optometry. 2010;81(1):35-9.

14. Hashemi H, Mehravaran S. Corneal changes after laser refractive surgery for myopia: comparison of Orbscan II and Pentacam findings. J Cataract Refract Surg. 2007;33(5): $841-7$

15. Kim SW, Sun HJ, Chang JH, Kim EK. Anterior segment measurements using Pentacam and Orbscan II 1 to 5 years after refractive surgery. J Refract Surg. 2009:25(12):1091-7.

16. O'Donnell C, Hartwig A, Radhakrishnan H. Comparison of central corneal thickness and anterior chamber depth measured using Lenstar LS900, Pentacam, and Visante AS-OCT. Cornea. 2012;31(9):983-8.

17. Huang J, Pesudovs K, Wen D, Chen S, Wright T, Wang X, et al. Comparison of anterior segment measurements with rotating Scheimpflug photography and partial coherence reflectometry. J Cataract Refract Surg. 2011;37(2):341-8.

18. Nemeth G, Hassan Z, Modis L Jr, Szalai E, Katona K, Berta A. Comparison of anterior chamber depth measurements conducted with Pentacam HR(R) and IOLMaster(R). Ophthalmic Surg Lasers Imaging. 2011;42(2):144-7.

19. Aramberri J, Araiz L, García A, Illrramendi I, Olmos J, Oyanarte I, et al. Dual versus single Scheimpflug camera for anterior segment analysis: Precisions and agreement. J Cataract Refract Surg. 2012;38(11):1934-49.

20. Salouti R, Nowroozzadeh MH, Zamani M, Ghoreyshi M, Salouti R. Comparison of horizontal corneal diameter measurements using Galilei, EyeSys and Orbscan II systems. Clin Exp Optom. 2009;92(5):429-33.

21. Kim SK, Kim HM, Song JS. Comparison of internal anterior chamber diameter imaging modalities: 35-MHz ultrasound biomicroscopy, Visante optical coherence tomography, and Pentacam. J Refract Surg. 2010;26(2):120-6.

22. Dominguez-Vicent A, Monsalvez-Romin D, Perez-Vives C, Ferrer-Blasco T, Montes-Mico R. Measurement of angle Kappa with Orbscan II and Galilei G4: effect of accommodation. Graefes Arch Clin Exp Ophthalmol. 2014;252(2):249-55.

23. Bland JM, Altman DG. Statistical methods for assessing agreement between two methods of clinical measurement. Lancet. 1986;1(8476):307-10. Comment in: Lancet. 2004;363(9403):164; author reply 164-5; Republished in: Int J Nurs Stud. 2010;47(8): 931-6.

24. U.S. Departament of Health and Human Services. Food and Drug Administration. Intraocular lens guide document [Internet]. Rockville: FDA [cited 2013 Jul 21]. Available from: http://www.fda.gov/ohrms/dockets/98fr/994052gd.pdf

25. Chen W, McAlinden C, Pesudovs K, Wang Q, Lu F, Feng Y, et al. Scheimpflug-Placido topographer and optical low-coherence reflectometry biometer: repeatability and agreement. J Cataract Refract Surg. 2012;38(9):1626-32.

26. Kohnen T, Terzi E, Kasper T, Kohnen EM, Bühren J. Correlation of infrared pupillometers and CCD-cameera imaging from aberrometry and videokeratography for determining scotopic pupil size. J Cataract Refract Surg. 2004;30(10):2116-23. Comment in: J Cataract Refract Surg. 2006;32(2):183-4; author reply 184; J Cataract Refract Surg. 2005;31(7):1267-8; author reply 1268; J Cataract Refract Surg. 2005;31(7):1266-7; author reply 1267.

27. Leung CK, Li H, Weinreb R, Liu J, Cheung CY, Lai RY, et al. Anterior chamber angle measurement with anterior segment optical coherence tomography: a comparison between slit lamp OCT and Visante OCT. Invest Ophthalmol Vis Sci. 2008;49(8):3469-74. 